\title{
Toward Integrating Information Literacy into Information Systems: A Case Study
}

\author{
Radwan Ali \\ Kennesaw State University, USA
}

\begin{abstract}
Information literacy (IL) practices are missing from most disciplines. Information Systems (IS) majors especially need these skills for their careers. The research focus of this paper addresses the information literacy (IL). A Web-based questionnaire was used to investigate undergraduate Business students on their understanding of IL and assessment of their respective abilities and skills. The study used IL standards adopted by the Association of College and Research Libraries [2]. We compared the performance of the of a sample of 82 from all majors. There were not stark differences among the majors. The main concern was the low average score, an indication of lack of IL culture in the undergraduate Business curriculum. We propose some treatments toward a wider IL integration framework.
\end{abstract}

\section{Introduction}

Information Literacy (IL) is a set of competencies (knowledge and skills) that denote one's ability to recognize and satisfy a need for information to solve problems [2]. IL has gained considerable attention because the dependence on information in today's society is increasing continuously [18]. The basic concept of information literacy is that cognitive and technical proficiencies are integrated to become a foundational set of information-centric competencies that include knowledge and skills.

The construct "information literacy" has existed in the literature since the 1970s. Zurkowski [20] introduced the term in the context of his work on the effort of the National Commission on Libraries and Information Science (NCLIS)'s initiative to create a national program for information literacy. The construct started gaining emphasis in the early 2000 s with the ubiquity of the Internet and its technologies [17]. Societal and business changes contributed to an increasing interest in IL [18]. IL is important to individual success, societal empowerment, and workforce readiness.

IL is helpful in preparing graduates with information skills they can and will use in their careers [2] and ethically because it emphasizes the lifelong learning aspect of information. Conley and Gil [9] investigated the value, relevancy, and implication of information literacy for undergraduate business students. They stressed the importance of information in decision-making by citing Drucker [11], considered the father of modern management. They shared that Drucker observed that organizations were becoming information-oriented and needed information-literate workforces.

Multiple IL initiatives introduced frameworks with standards and competencies. For example, the Association of College and Research Libraries (ACRL) generated the IL framework that included five standards and twenty-five performance indicators for IL in Science and Engineering/Technology. The performance indicators, in turn, included outcomes for assessment. Figure 1 shares the five standards. Both, higher education and businesses acknowledge the importance of IL They recognize the need for a college graduate to be able to solve problems, manage information and communicate solutions. With such, IL should be more prevailing in academia and the workplace. Much of the informing science literature [13]. Yevelson and Bronstein [19] pointed out disconnect among the various stakeholders: students, faculty, and library. All seem to realize and tout the importance of IL, but each had a different perspective on how IL should be addressed.

Expectations in the workplace have changed with more dependence on information. Consequently, organizations are attempting to adapt by seeking information-literate workforce. 


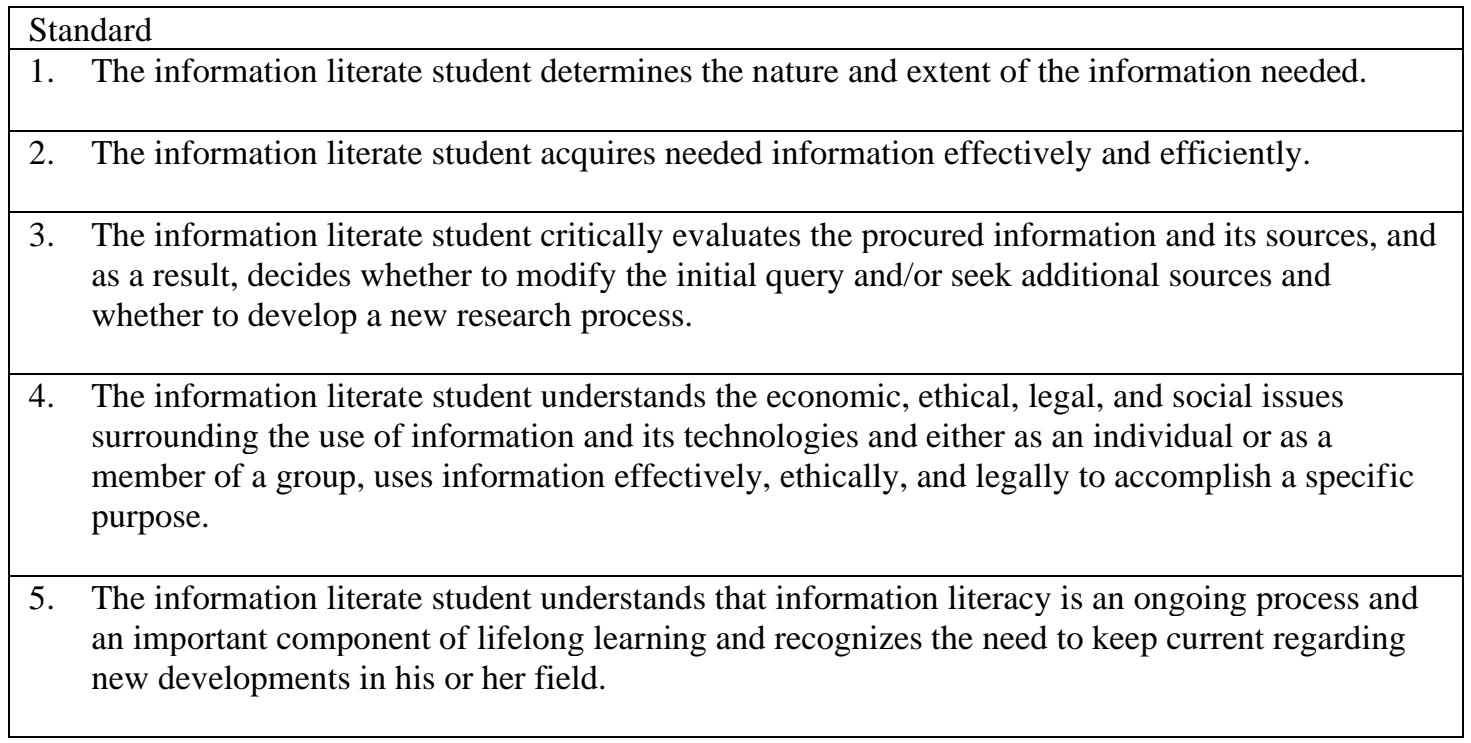

Figure 1. ACRL IL standards

\begin{abstract}
High-performing organizations promote an information-centric workplace [6]. These organizations seek talented college graduates with IL proficiencies to advance organizational performance [6]. Conley and Gil [9] conducted a study that showed lack of IL awareness in the workplace. $72 \%$ of surveyed business professional in a career fair shared that they had not hear of IL. The researcher rationalized that IL was not widely known because it was confined to the Library instead of all aspects of higher education.

One can safely assume that universities and colleges believe that they produce a prepared workforce that is consistent with the marketplace's expectations. The workforce is expected to be prepared with the right proficiencies such as those of information literacy. Weiner [18] claimed that research on IL's implications on the workplace was limited.
\end{abstract}

\section{Motivation}

Zurkowski [20] defined the information-literate individuals as those who are "...trained in the application of information resources to their work." [20]. IL should be seen as a lifelong wholesome learning process that helps an individual solve organizational problems [4]. IL has been equated with problem-solving often [18]. College students need IL to differentiate themselves in the workplace [7]. IL entails skills and knowledge for all careers. Generally, there are two ways to gain skills and knowledge: 1) through formal education like college, or 2) on-job training [13]. Because IL is not usually discussed in human resource practices, it is important to investigate it in the formal education venue. Cannon et al. [7] stressed the information workers need research skills to understand communication from clients. They need to use research plans to find information and materials to analyze problems, plan and design solution.

The research project argues that IL should be a second nature for Information Systems (IS) Majors to enrich their careers. There is not worthy research that explores IL practices in the business school in general, and particularly, the IS curriculum. Moreover, there is no IL culture in most disciplines. IL practices are missing from most disciplines because IL is mentioned mostly in association with the library sciences. Badke [4] explains that IL “... is invisible to academia because it is misunderstood..." [4] and that academics confuse it with computer literacy. Such gap calls for our study, especially because IS majors are projected/aspiring to be information workers in their careers.

\section{Literature Review}

The review section aims to share a survey of literature on information literacy and the need for it in the Information Systems curriculum. A large portion 
of literature associates IL to library sciences and discusses the construct with respect to seeking, locating, and evaluating information. We intended to use the section to elaborate on IL from various sources of information. First, we sought the keywords "information literacy" in IS-discipline journals using Google Scholar. There was not any worthy mention of the construct. We sought the construct/keywords in the archives of the Journal of Information Systems Education (JISE). We found three instances: [16], [15], [14].

Pratt et al. [16] mentioned information literacy in their discussion of the IS curriculum and liberal education learning outcomes. The article mentioned IL twice. The first as one of the Intellectual and Practical Skills as chartered by Association of American Colleges and Universities (AAC and U). The second mention was as a descriptor for Communication within the common liberal education descriptors within the IS 2010 core courses. Further, the article argued for integrating education learning outcomes in the IS curriculum for the sake for developing the IS graduates as future problem-solvers and business leaders.

Nelson et al. [15] discussed IL within the context of digital literacy. Their study sought to investigate digital literacy needs. They shared that their investigation was initiated based on concerns about a computer literacy course. They felt that course was limited in providing the enrolled students with solid competencies and skills for today's workplace. Their approach to research revolved around digital literacy as technical skills for the workplace. They discussed $\mathrm{IL}$ as an important component for an improved design of said course. They argued that these literacies could not and should not be limited to individual courses. They called for wider adoption and integration in the IS curriculum.

Lehman [14] discussed IL in an article that shared the design of an MBA course for business information sources. She reasoned that it was essential to Business graduates needed to be prepared to an informationoriented society with the ubiquity, scope and reach of information. The course was interdisciplinary as it combined traditional research methods, library science, and management information systems. The experience shared included many lessons. The most relevant was that students with advanced computer skills may not be information-literate. It was and still is important to differentiate IL from computer literacy.

Research has shown that IL skills and rigorous practices are important for lifelong learning and career success [18], [9]. IL is closely associated with Library Science, there is a surge for IL skills in higher education [18] different disciplines like Medicine, Nursing, and Chemistry [18]. Weiner [18] showed concern that IL was not receiving attention in the workplace as it was vetted mainly in educational contexts. She used multiple research sources to emphasize the need for information skills in the workplace because they are essential to solve problems and creating organizational value.

Changes in the information sciences and the articulation of an educational paradigm have helped spread the IL concept [17]. The noble goal of IL framework is teaching college students problemsolving that will benefit society and business alike. A large part of the literature seems to look at IL in educational settings with minimal attention for the workplace [4]. That limits the great potential of IL's effect on society, including business, outside the academy.

The section shared some of the literature on information literacy. One of the highlights (or lowlights) section was the lack of IL in IS relevant publications. Only the JISE published articles that discussed or mentioned IL. We intend for the study to serve as a renewal of the importance of IL in the IS curriculum.

\section{Theoretical Framework}

Our study adopts Connectivism for its theoretical framework. It is a learning theory that was developed with a collective take on previous theories: behaviorism, constructivism, and constructionism. The theory is based on many principles that assert that...

- Learning depends on connection of information sources,

- Learning and technology are linked,

- Learning results in knowledge,

- Connections with other perspectives is central to learning, and

- Evaluating information is important to learning.

Siemens [60] argues that learning is complex, chaotic and can be found in human subjects and nonhuman objects. He emphasizes the strong relationship between learning and knowledge. He believes that both depend on networks of different types of sources (human and non-human). These networks can serve as solution of renewed knowledge because knowledge changes rapidly and could be become obsolete. Thus, these networks will always have connections with new knowledge. Our current study sees it as emphasis to the lifelong nature of information literacy.

Chatti et al. [8] saw Connectivism as an alternative learning theory that distinguishes itself from other social learning theories with a more 
dynamic and open knowledge-centered learning model. They saw it as a network metaphor for learning. Dunaway [12] explained that Connectivism thrives on that IT plays an important role in producing knowledge. She emphasized that Connectivism focused on the learners' abilities to connect information to their environments and needs. McBride [47] hailed Connectivism as a natural evolution of Constructivism because it addresses the technological advances of the last three decades.

In context of our study (workplace readiness and performance), Connectivism has school and workplace implications. For the school settings, they see that students can produce their own knowledge by networking among themselves. As for the workplace, today's workplace can adopt connectivism for networking diverse minds and ideas to create organizational knowledge. They acknowledged that Connectivism has its detractors.

Connectivism is appropriate for the study because of its congruence to the IL standards as chartered by ACRL [2]. These IL standards were modified to reflect the realities of today's information-oriented society. The study is interested in productivity of Business majors in organizational settings. IL's five standards (see Figure 1) underline a strong performance tone. We use these standards and Connectivism to guide the study.

\section{Research Questions}

IL is the core interest of our study. We aimed to investigate the level of IL practices in Business majors. [11], the father of modern management, presented the concept of knowledge worker in the context of management theory and practice. He theorized that organizational productivity would depend on informed workforce. Some of his writings pointed to the evolvement of information society. Because the business school aims to be responsive to the needs of the marketplace, it is imperative to continuously assess the business curricula.

It is important to offer a curriculum that prepares students to solve problems and make decisions, especially emphasizing the nature of information work. In a comparison study of IS and CS students' problem solving, the researchers underscored the importance of the learning experience. They wanted faculty to "...develop instructional strategies that will both acquaint students with the challenges they will face and help them meet those challenges..." [17].

Baxter et al. [5] concurred that higher education should prepare their students with information skills. Their study examined predictors of success in a college computer science course. They recommended that business schools develop these students' skills further with less emphasis on theory. Cannon et al. [7] believed that business students were not prepared to approach and solve authentic problems because the business school's curriculum was limited by its delivery methods institutions. Aasheim et al. [1] investigated whether perceptions of entry-level skills for information workers were different between academia and industry. They surveyed 350 IT managers and 78 faculty members. They found that there were agreements and disconnects between academia and industry on skills a graduate should possess.

The study aims to explore the reach of IL in student preparation. We posit the following research questions: 1) What level of IL skills do Business Majors demonstrate? And 2) Do Business Majors illustrate higher level of IL skills in comparison with other Business Majors?

Yevelson-Short and Bronstein [19] interviewed students, faculty, and librarians for a study of their perceptions of IL. The study highlighted a huge disconnect among the three groups. The students felt that their IL skills were lacking, the faculty thought that the students would pick IL skills during their studies, and the library was aware of the students' IL deficiencies and introduced remedy initiative. These initiatives were hard to implement in the current curriculum because of logistics. The findings suggested that it was important for the faculty, library and students to collaborate on any IL initiatives. Though the study was limited to one school, it is noteworthy that the students realized their limitations, and acknowledged the need for help from faculty and the library.

\section{Methodology}

The study of IL skills in the Business school started with 183 students in six Business courses (IS and MGMT). They were invited via email to participate in a Web-based questionnaire. They were informed that the participation was optional in the email Subject line and in the body of the email letter. That optional participation was also emphasized in the introduction to the questionnaire. The questionnaire included the IRB details, the purpose of the study, and a consent form. The participants were offered an incentive of 10 points to be added to their final total points in their respective courses for complete questionnaires. The questionnaire included 43 questions, 25 of which comprised a quiz that intended to assess their IL skills. Additional 15 points were offered for the highest $20 \%$ of the scores on the IL quiz. 83 students took the questionnaires and 82 completed it. The incomplete questionnaire was 
eliminated. Two of the completed questionnaires belonged to non-business majors. These were also eliminated $(n=80)$ as well. Table 1 displays the breakdown of the complete questionnaire by major.

Table 1. Completed questionnaires by Major

\begin{tabular}{l|c}
\hline$\underline{\text { Major }}$ & $\underline{\underline{\text { Count }}}$ \\
\hline Accounting & 10 \\
Economics & 2 \\
Entrepreneurship & 2 \\
Finance & 5 \\
International Business & 1 \\
Information Systems/ISA & 7 \\
Management & 37 \\
Marketing & 14 \\
Sales & $\underline{2}$ \\
Total & $\mathbf{8 0}$ \\
\hline
\end{tabular}

The IL quiz (Q19 through Q43) was included within the questionnaire with 5 items corresponding to each of the IL standards (see Figure 1). Table 2 shows question mappings to the corresponding IL standards. We used SPSS software for data analysis.

We started with validating the instrument [10] to assess its effectiveness in capturing the essence of the research. Our analysis produced a Cronbach's [10] alpha $(\alpha)$ of .855 . The solid figure resulted from improvements based on prior assessment. We ran an experiment in three different classes in a previous semester (Summer 2019) of a sample size (n) of 43 students. Based on that experiment, we improved the questionnaire to its current form. The current study was conducted in different classes during Fall 2019 term.

\section{Results and Analysis}

In this research work we consolidated the 5 questions (see Table 2) that correlated with the standards and scored these separately for the sample and then scored these for the IS Majors and the remaining Business Majors separately for comparison. The data were downloaded and saved in SPSS format. We started with the scores on the 25-question quiz that was included in the questionnaire. The average score for the sample was 11.94 out of 25 (45.75\%). The highest score was 18 , and the lowest was 4.45 of the student scores were higher than the average.

For IL Standard 1 (Articulation of information need), the sample showed a mean of 2.7750 . We also calculated the mean for the IS/ISA Majors; it came to 2.8571 compared to 2.7671 for the remaining 73
Business Majors. The standard deviation $(\sigma)$ for the former group was .6900 while it was 1.1609 for the latter. Consequently, $\sigma$ for the whole sample was 1.1248 .

For IL Standard 2 (Acquiring information efficiently and effectively), the IS/ISA Majors mean score was higher (2.2857) than that of the other Business Majors. $\sigma$ for the first group was 1.1127, and the second group had $1.0922 \sigma$. In some cases, participants may not have accurate perceptions. Another reason may be that they thought of accomplishments without accounting for struggles. Another reason is that because participants may not have benchmarks or baselines.

For IL Standard 3 (Information critical evaluation), IS/ISA Majors produced a mean of 1.7143 compared to 2.0411 mean for the other Business Major. It was the lowest average for the IS/ISA student scores on any of the standards. In our analysis of the various items, we did not delve into the reasons behind specific lows scores. The corresponding low $\sigma(.9512)$ emphasized a need for action as the majority of these IS/ISA students erred with IL3.

For IL Standard 4 (economic, ethical, legal, and social issues), the participating IS/ISA students did better: Their mean score was 3.000 and the mean for the other Majors was 2.6712. The $\sigma$ relayed 1.4142 and 1.2699 respectively. The responses to the five questions of IL4 showed that the students are aware of various aspects associated with using information.

For IL Standard 5 (IL is a lifelong process), the scores were the highest for two groups out of all standards. The IS/ISA Majors earned a mean score of 3.5714 while the other Business Majors scored a mean of 3.3151. And $\sigma$ was .7868 and 1.0392 respectively. The mean scores here were encouraging as they showed that the students in the sample understood the importance of IL in their careers. On three of the five questions for IL5, their percentages for the correct response were $93 \%, 95 \%$, and $95 \%$. One of the quiz questions (Q43) for that standard sought the students' vision on professional development. Most of the participating students $(93 \%)$ answered that they were responsible for setting up a professional development plan. Though the student average score on the quiz was low $(45.75 \%)$, there were some promising opportunity for developing the students' IL skills for better performance.

The results showed that the students who participated in the current pilot study had a low score on a quiz that assessed their IL skills. The main concern was the low average score. In order to treat such weak performance (an indication of lack of IL culture in the IS curriculum), we strive for the study to provide such treatment. We propose a potential framework in the next section. 
Table 2. IL standards and Quiz question mappings

\begin{tabular}{|c|l|}
\hline IL Standard & Corresponding Quiz items \\
\hline S1 & Q21, Q22, Q33, Q40, Q41 \\
\hline S2 & Q23, Q29, Q34, Q35, Q42 \\
\hline S3 & Q27, Q28, Q32, Q38, Q30 \\
\hline S4 & Q19, Q20, Q31, Q37, Q39 \\
\hline S5 & Q24, Q25, Q26, Q36, Q43 \\
\hline
\end{tabular}

Table 3. IL Template for Assignments for Introductory IS Courses

\begin{tabular}{|l|l|l|}
\hline \multicolumn{1}{|c|}{ Question } & Your response & $\begin{array}{c}\text { What IL standard aligns } \\
\text { with this requirement? } \\
\text { Please justify your } \\
\text { answers. }\end{array}$ \\
\hline $\begin{array}{l}\text { 1. What is the primary requirement of the } \\
\text { Business Case task? }\end{array}$ & & \\
\hline $\begin{array}{l}\text { 2. What are the resources needed to } \\
\text { complete the requirements of the Business } \\
\text { Case? }\end{array}$ & & \\
\hline 3. How would you obtain these resources? & & \\
\hline $\begin{array}{l}\text { 4. How would you document these } \\
\text { resources? }\end{array}$ & & \\
\hline $\begin{array}{l}\text { 5. What are the ethical, legal, and economic } \\
\text { measures or concerns you need to consider } \\
\text { with respect to these resources? }\end{array}$ & & \\
\hline $\begin{array}{l}\text { 6. What future professional developments do } \\
\text { you foresee for yourself based on this } \\
\text { experience? }\end{array}$ & & \\
\hline
\end{tabular}

Table 4. Task Planning Template for Technical IS Courses

\begin{tabular}{|l|l|l|}
\hline Task Name: & \multicolumn{2}{|l|}{} \\
\hline Deliverable: & $\begin{array}{l}\text { What is the expected outcome of this task (one outcome / } \\
\text { template)? }\end{array}$ \\
\hline Resources: & Please list of all resources that will be needed to complete this task. \\
\hline Steps to Solution: & $\begin{array}{l}\text { Please list the steps you believe } \\
\text { will help you complete this } \\
\text { task: }\end{array}$ & $\begin{array}{l}\text { Please share the details of how } \\
\text { you will complete each step } \\
\text { you listed in the previous cell: }\end{array}$ \\
\hline Testing your solution & $\begin{array}{l}\text { Please share your plan on how } \\
\text { you will test your proposed } \\
\text { solution: }\end{array}$ & $\begin{array}{l}\text { Do you have other solution } \\
\text { alternative(s)? If so, please list: }\end{array}$ \\
\hline $\begin{array}{l}\text { Reflection and future } \\
\text { developments: }\end{array}$ & $\begin{array}{l}\text { Please share the new } \\
\text { knowledge / skills you have } \\
\text { acquired after completing this } \\
\text { task: }\end{array}$ & $\begin{array}{l}\text { What future developments do } \\
\text { you see for your task and for } \\
\text { yourself? }\end{array}$ \\
\hline
\end{tabular}




\section{IL Framework for the Curriculum}

In this paper we used the IS curriculum at our current Business school as a starting point for the framework. We grouped courses into three categories:
Introductory/inventory courses, planning courses, and technical courses. Then, we mapped the IL Standards to their respective categories where we saw potential for infusing or implementing the Standards (see Figure 2).

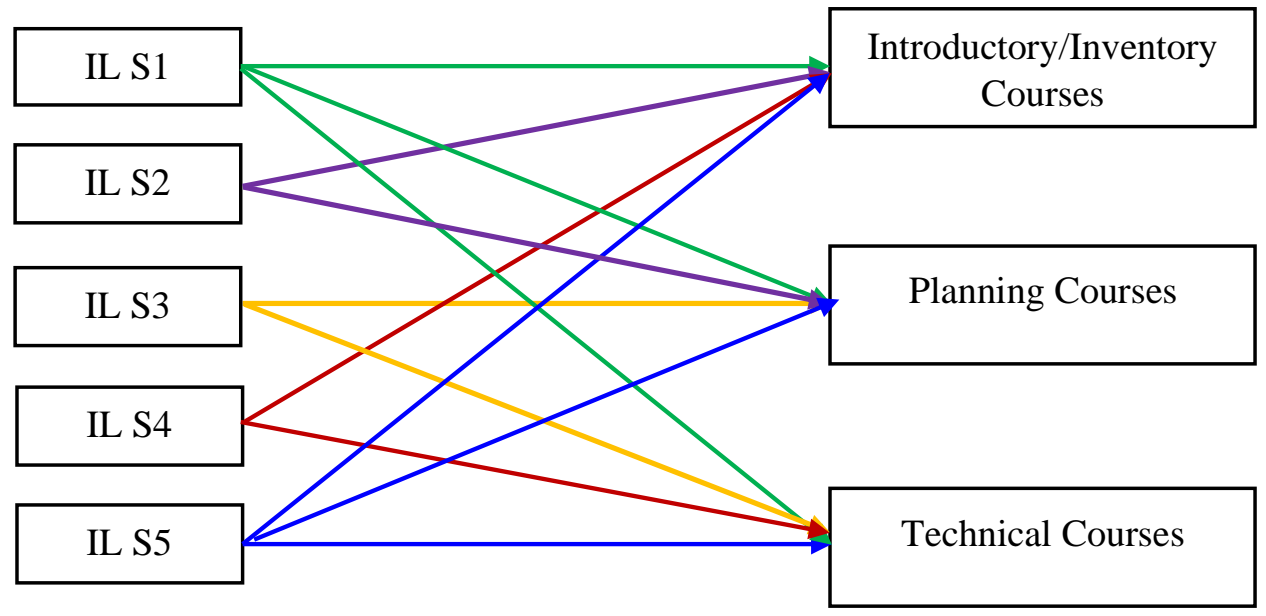

Figure 2. Proposed alignment of IL standards to course categories

The proposed framework does not intend an overhaul for the IS curriculum. Rather, it presents an enrichment opportunity for IS graduate preparation for today's information-centered workplace. We rationalize our approach next.

\subsection{Introductory and Inventory Courses}

We propose that Sophomore and some Junior level IS courses are included in current category. The nature of such courses, as general requirements for all business Majors, they provide a foundation for basic IL skills such as articulation of information need and acquiring needed information. We see that IL Standards 1 and 2 will be good fits (see Table 3 ). The former is a good first step to ease the students into acquiring effective articulation skills. Whether in articulation it is asking the right question during class lecture and discussion or into an online blog or discussion thread. One of the exercises we implement in every class is concluding the class with takeaways: the instructor requires the students to share a onesentence takeaway from that day's lecture. If a student cannot do it in one sentence, meaning he/she rambles on, we move another student. Then, we come back to the one who did not do it for another attempt. It is obvious that we will not get all students to speak in a large size class. They will get turn the next class lecture.

\subsection{Planning Courses}

We envisage planning courses category to include subjects such as Business Process Management, Project Management, IS Strategy, IT Infrastructure, and Systems Analysis and Design. These courses afford their students outstanding opportunities to explore the business value of Information Systems. They will have a great potential for learning and documenting business problems and solution planning. IL Standards 1, 2, and 3 could be used here. An example would be articulating the main requirement to solve a business problem. Then, the students will identify the required resources. Because the basis for the solution will reside in information, the students should be introduced to managing the information they acquired for respective business problem. For example, in a Project Management course, students can create a timetable based on information acquired from communication with a client. Prior to creating and producing the timetable, the students can document the communication with the client and confirm the communication from their documents to the client. Furthermore, they will document the communication and feedback from the client after they (the students) present the timetable.

\subsection{Technical Courses}

This category includes all development (programming) courses in addition to any courses that 
include other technical skills. While these courses focus on acquiring coding skills, they present opportunities for students to use IL skills in planning and concluding their programming assignments or projects. For example, having the Capstone course included here, students may use IL skills in activities such documentation of development, user manuals, debugging logs, etc. Another example, if a student is taking a course where she/he is learning a new programming language, it would be wise for the student to find external sources to enhance her/his classroom learning and document these sources and how she/he found them. Furthermore, the student would benefit from using a reflective journal that will chronicle her/his challenges with the new programming language. We propose a sample template (see Table 4) that includes a number of steps to help a student break his/her programming projects into tasks with room for reflection on learning.

Implementing IL practices in the IS curriculum requires collaboration among three main stakeholders: the faculty, students, and the academic library. The faculty, being a pivot party to the matter, can take an active role in planning and implementing IL initiatives in their courses. We see possibilities of sessionoriented activities or specific IL assignments that align with the matter of the respective course. We also see that faculty will seek the academic library's help in educating students on IL practices.

In its role, the library must be active in ensuring that the IL-relevant literature is readily available to the students. In addition, the library staff will help educate the respective faculty on IL skills as well. The library will extend the faculty's reach by helping the students who visit, or have the librarians visiting the classroom and promoting and teaching IL skills.

In turn, the students must participate actively by completing the requirements of their respective ILoriented class assignments and projects. An important factor for student initiative is the understanding of the essentiality of professional development. While faculty should focus effort toward cultivating a culture of IL, the students' buy-in become essential to spreading that culture. Students must understand that their career success depends on their IL abilities in today's information-centered workplace.

This may include introduction of intentionally designed IL-centered course assignments, and possibly, IL class activities. With collaboration among these various parties, the implementation of the framework is a key step toward an organization-wide use of the proposed structure. Each of these groups has a set of responsibilities toward the framework implementation.

\section{Limitations}

There were some limitations for the study. The most obvious is the sample size $(n=80)$. The researcher hoped the study to serve as a first step for more inclusive Business school-wide study in the very near future. The study participants came from six Sophomore and Junior-level Business courses (Management and IS). The six courses had a combined population of 183 students. Only 83 students started the optional activity.

The sample size might have contributed to the second limitation: a low Cronbach's alpha $(\alpha=.450)$ of the quiz portion of the questionnaire. alpha is a measure of reliability or consistency of that set of question. While the questionnaire consisted of 43 questions including the consent to participate, we tested for $\alpha$ for the 25 questions that comprised the quiz (assessment) of the participants. We noted in the Methodology section that $\alpha$ was .855 for the whole questionnaire (43 questions). In order to treat the quiz's low $\alpha$ issue, we planned to interview the participants in the current study for their opinions on the quiz's questions to see if there were confusing questions and to assess their rationale behind some of their answers. We believe that approach will help us design and articulate the next version of the quiz for a higher $\alpha$, and consequently, robust more reliable questionnaire.

\section{Conclusion}

The research project explored IL skills in undergraduate Business Majors. The paper shared the findings of a pilot study. Based on these findings, the paper proposed a framework for implementing IL practices into the Information Systems curriculum. The literature review shared within the paper showed that IL initiatives were limited to a small number of disciplines in higher education. That review showed a clear lack of IL in the Business school in general, and especially, in the IS discipline. We do not intend to disrespect the current IS curriculum or the abilities of faculty. We believe that having a set structure can be helpful to prepare IS gradates for successful information-oriented careers. The framework proposed here provides a big picture approach that can be a starting point for a wider discussion on such important matter.

We intended for the pilot study to be a prelude to more IL-focused research projects. We envisage a research stream that will include a Business Schoolwide study that includes all majors. Such study will provide opportunity to compare IL skills comparison among classes (Freshmen, Sophomores, Juniors, and 
Seniors). Another opportunity will be comparing Majors, and specifically, IS majors to other Business majors. Also, it would become imperative to investigate implementing new IL-focused case studies such as class-session modifications or implementing new assignments. It will lend itself to study collaboration projects between the IS discipline and the Library.

\section{References}

[1] Aasheim, C. L. and Williams, S. R. (2009). Knowledge and Skill Requirements for Entry-Level Information Technology Workers: Do employers in the IT industry view these differently than employers in other industries? The Journal of Information Systems Education, 20(3), 349-355.

[2] ACRL (2000), Information Literacy Competency Standards for Higher Education, American Library Association, Chicago, IL.

[3] Alshare, K. A.; Lane, P. L., and Miller, M. (2011) Business communication skills in information systems (IS) curricula: Perspectives of IS educators and students. Journal of Education for Business, 86 (3), 186-194.

[4] Badke, W. (2011). Why Information Literacy Is Invisible. Communications in Information Literacy, 4 (2), 129-141.

[5] Baxter, J. T.; Hungerford, B.; and Helms, M. M. (2011). Predicting success in the introduction to computers course: GPA vs. student's self-efficacy scores. Information Systems Education Journal, 9(2), 75-85.

[6] Braun, N. M. (2004). Critical thinking in the business curriculum. Journal of Education for Business, 79(4), 232 236.

[7] Cannon, D.; Klein, H.; Koste, L. and Magal, S. (2004). Curriculum Integration Using Enterprise Resource Planning: An integrative case approach. The Journal of Education for Business, 80, 93-101.

[8] Chatti, M.A., Jarke, M. and Quix, C. (2010). Connectivism: the network metaphor of learning. Int. J. Learning Technology, 5 (1), 80-99.

[9] Conley, T. M. and Gil, E. L. (2011). Information literacy for undergraduate business students: Examining value, relevancy, and implications for the new century. Journal of Business and Finance Librarianship, 16, 213-228.

[10] Cronbach, L. J. (1971). Test validation. In R. L. Thorndike (Ed.), Educational measurement (2nd ed.), 443507. Washington DC: American Council on Education.

[11] Drucker, P. (1994, August). Infoliteracy. Forbes: ASAP, 104.
[12] Dunaway, K. M. (2011). Connectivism. Reference Services Review, 39(4), 675-685.

[13] Ezziane, Z. (2007). Information technology literacy: Implicationson teaching and learning. Journal of Educational Technology and Society, 10(3), 175-191

[14] Lehman, L. M. (1995). Drivers' Ed for the Information Highway: A Required Course for MBA Students. Journal of Information Systems Education, 7(1), 30-33.

[15] Nelson, K., Courier, M., and Joseph, G. W. (2011). Teaching Tip: An investigation of digital literacy needs of students. Journal of Information Systems Education, 22(2), 95-110.

[16] Pratt, J., Keys, A., and Wirkus, T. (2014). Preparing Information Systems Graduates for a Complex Society: Aligning IS Curricula with Liberal Education Learning Outcomes, Journal of Information Systems Education, 25(1), 35-44.

[17] Špiranec, S.; and Zorica, M. B. (2010). Information Literacy 2.0: hype or discourse refinement? Journal of Documentation, 66(1), 140-153.

[18] Weiner, S. (2012). Institutionalizing Information Literacy. The Journal of Academic Librarianship, 38(5), 287-293.

[19] Yevelson, A. and Bronstein, J. (2018). Three perspectives on information literacy in academia: Talking to librarians, faculty, and students. College and Research Libraries, 79. 535-553.

[20] Zurkowski, P. G. (1975). The Information Service Environment: Relationships and Priorities. Related Paper No. 5. 